\title{
Políticas Educacionais Nos Governos Lula e Dilma: Impactos na Expansão do Ensino Superior e Profissional
}

Maria Alice de Freitas Marques ${ }^{1}$

\begin{abstract}
Resumo: Esse artigo versa sobre um recorte histórico e bibliográfico das políticas educacionais nos governos Lula e Dilma, como tais ações influenciaram na expansão do ensino superior e profissional de acordo alguns autores da pesquisa em educação e documentos institucionais. A discussão visa expor a situação das modalidades de ensino citadas no que diz respeito a recursos, investimentos, crescimento e mudanças em paradigmas de oferta de cursos e a formação do público alvo. Como tudo isso influenciou na perspectiva educacional do país nesse período e quais os retornos e impactos assimilados por educadores e instituições de ensino são um dos objetivos desse trabalho. A análise bibliográfica buscará citar fatos e consequências que marcaram esse período democrático na construção de mais uma etapa da educação brasileira, fornecendo um material relevante para docentes e futuros pesquisadores educacionais.
\end{abstract}

Palavras-chave: Educação, Políticas Educacionais, Ensino Superior, Expansão, Profissional.

\section{Educational Policies In Lula governments and Dilma: Impacts On Expansion Of Higher Education And Professional}

\begin{abstract}
This article deals with a historical and bibliographic review of educational policies in the Lula and Dilma governments, as these actions influenced the expansion of higher and professional education according to some authors of research in education and institutional documents. The purpose of the discussion is to present the situation of the mentioned teaching modalities with respect to resources, investments, growth and changes in paradigms of course offer and the formation of the target public. How all this influenced the educational perspective of the country in that period and what returns and impacts assimilated by educators and educational institutions are one of the objectives of this work. The bibliographic analysis will seek to cite facts and consequences that marked this democratic period in the construction of another stage of Brazilian education, providing a material relevant to teachers and future educational researchers.
\end{abstract}

Keywords: Education, Educational Policies, Higher Education, Expansion, Professional.

\footnotetext{
${ }^{1}$ Graduada em Tecnologia em Mecatrônica Industrial pelo Instituto Federal de Educação, Ciência e Tecnologia do Ceará, Especialista em Metodologia da Docência do Ensino Superior pela Faculdade Vale do Jaguaribe. Aluna do Programa de Mestrado Profissional em Educação - MPEDU da URCA. Contato: joliealice@ hotmail.com.
} 


\section{Introdução}

Os governos Lula e Dilma representaram dentro do período democrático brasileiro uma significativa mudança em alguns referenciais no que diz respeito à educação superior e profissional. As políticas educacionais colocadas em prática nesse período foram analisadas por diversos pesquisadores, entre eles Demerval Saviani, que buscou traçar um perfil dos impactos de tais medidas no cenário da educação brasileira. Alguns desses impactos e transformações ocorridas na época serão levantados nesse artigo, tentando dialogar de forma crítica esses anos em relação à política e a educação, levando em consideração o contexto histórico, fatos relevantes dos mandatos presidenciais anteriores e suas respectivas ações que tiveram consequências ou continuidade nos demais governos.

Entre os pontos principais dessas políticas educacionais nos governos Lula e Dilma são possíveis destacar: a expansão do ensino superior seja ele presencial ou à distância, privado, público e do ensino profissional. Para realizar a análise dessas ações serão levantados bibliograficamente documentos institucionais dos programas de governo da época como FIES, o Financiamento Estudantil da Educação Superior, o PROUNI, REUNI e PRONATEC, bem como outras medidas políticas adotadas no incentivo dessa expansão.

Em 1996 nós tínhamos 922 instituições de nível superior, sendo 211 públicas (23\%) e 711 privadas (77\%). Em 2005 o número total das instituições se elevou para 2.165 com 231 públicas $(10,7 \%)$ e 1.934 privadas $(89,3 \%)$. Por sua vez, no que se refere ao alunado nós tínhamos, em 1996, um total de 1.868.529 alunos, sendo 725.427 $(39,35 \%)$ em instituições públicas e 1.133 .102 (60,65\%) em instituições privadas. Já em 2005 a relação foi a seguinte: Total de alunos 4.453.156, sendo 1.192.189 $(26,77 \%)$ no âmbito público e 3.260 .967 (73,23\%) no âmbito privado. Observe-se, por fim, que em 2007, primeiro ano do segundo mandato do governo Lula, o percentual dos alunos nas instituições públicas continuou caindo tendo chegado a $25,42 \%$ em contraste com o número das instituições privadas que passou para 74,58\% atingindo, portanto, dois terços do alunado. (SAVIANI, 2010, p. 14)

De acordo o autor, os dados de crescimento em matrículas em instituições de ensino superior foram significativos na mudança do governo Fernando Henrique Cardoso (FHC) para o governo Lula, e mais ainda ao se levar em consideração o âmbito privado. Diante do exposto a verificação de políticas que foram aplicadas para a obtenção desses dados é de fato relevante para serem analisadas em um recorte que vai além de medidas educacionais e como também econômicas. 
Dentro da análise bibliográfica que será realizada nesse artigo, uma das observações levantadas é que um dos fatores motivadores para todas essas políticas educacionais é a economia, o governo brasileiro historicamente tais medidas baseando-se em níveis econômicos, perfis de mercado, investimentos e incentivos internacionais. Ao final desse trabalho será possível expor de forma mais clara para um educador, como as políticas governamentais e seus interesses impactam na educação que vivemos no dia a dia, no que diz respeito ao ensino superior.

As diretrizes institucionais dos governos juntamente com o contexto político e histórico do período serão analisadas e expostas neste artigo com o auxílio da pesquisa de alguns autores, para que seja possível na conclusão desse trabalho obter um panorama crítico de muitas das ações implantadas. Ao se tratar da educação superior e profissional, atualmente, diversas mudanças já ocorreram, ou seja, para se incentivar e fornecer bases em novas pesquisas e intervenções de educadores é preciso ter a noção das políticas educacionais executadas, agregando assim um suporte teórico e histórico de impactos e consequências vividos nesse período.

\section{Políticas de FHC e a Criação do Fies}

Uma importante base teórica para a compreensão desse período é constituída de decretos e normativas institucionais do governo ao legislar na direção das políticas educacionais as quais se propõe, de forma que ao estabelecer novas regras e orientações para instituições de ensino superior e educação profissional provoca mudanças no modo como a educação brasileira se desenvolve em determinadas conjunturas.

Além dos documentos institucionais, o material bibliográfico de pesquisadores em sobre medidas adotadas pelo governo em relação à expansão da educação superior também constitui de ricas informações para o entendimento desse período da forma crítica a qual este artigo se propõe.

Com o intuito de contextualizar as políticas de expansão nos governos Lula e Dilma, é necessário tratar como o governo anterior, o de FHC, Fernando Henrique Cardoso, tomou um rumo de reformas políticas dentro de pautas da educação que indicaram um crescente do ensino 
superior oferecido no país no âmbito privado. Saviani (2010) expõe as mudanças realizadas no governo de FHC quando cita que:

\begin{abstract}
A partir da década de 1990 num processo que está em curso nos dias atuais emerge nova mudança caracterizada pela diversificação das formas de organização das instituições de ensino superior alterando-se o modelo de universidade na direção do modelo anglo-saxônico na versão norte-americana. Em consequência dessa mudança freou-se o processo de expansão das universidades públicas, especialmente as federais, estimulando-se a expansão de instituições privadas com e sem fins lucrativos e, em menor medida, das instituições estaduais. Essa foi a política adotada nos oito anos do governo FHC, o que se evidenciou na proposta formulada pelo MEC para o Plano Nacional de Educação apresentada em 1997. (SAVIANI, 2010, p. 13)
\end{abstract}

Segundo o Saviani (2010), as alterações no processo de expansão das instituições de ensino superior que culminaram nas políticas dos governos atuais, se deram com as iniciativas do então presidente Fernando Henrique de acompanhar as tendências norte-americanas de desenvolvimento, onde após análises estatísticas o Brasil apresentou índices que não completavam $12 \%$ da população na faixa etária entre 19 e 24 anos com acesso ao ensino superior, o que estimulou as aprovações da Lei de Diretrizes e Bases (LDB) da Educação e o PNE (Plano Nacional de Educação) com o intuito de reverter esses índices diante do cenário econômico internacional através do Ministério da Educação (MEC).

A aprovação da LDB elaborada pelo senador Darcy Ribeiro, em conjunto com os
setores vinculados ao projeto dos privatistas e do PNE, absolutamente afnado com
este projeto, somados ao conjunto de leis, medidas provisórias, decretos e projetos de
lei, elaborados neste período, demonstra que o governo Cardoso realizou um profundo
reordenamento político e jurídico, criando as bases para a privatização, em larga
escala, da educação superior brasileira. (LIMA, 2005 apud MORAES, 2015, p. 22).

Da forma citada por Moraes (2015), as medidas privatistas incentivaram o setor da educação superior estimulando matrículas, criação de novos cursos e instituições de ensino, de uma forma a condicionar a oferta da educação superior ao capital privado. A partir daí iniciouse os programas de oferta de financiamento, o primeiro deles, ainda dentro do governo FHC foi o FIES.

Criado pela medida provisória MP $\mathrm{n}^{\circ} 1.827$, de 27/05/99, regulamentado pelas Portarias MEC n 860 , de 27/05/99 e 1.386/99, de 15/19/99 e Resolução CMN 2647, de 22/09/99, o FIES foi institucionalizado como Lei em 2001 com o número 10.260, dispondo como Fundo de Financiamento ao estudante do Ensino Superior e dando outras providências.

Na Lei 10.260/2001 é citado que: 
Art. $1^{\circ}$ É instituído, nos termos desta Lei, o Fundo de Financiamento Estudantil (Fies), de natureza contábil, vinculado ao Ministério da Educação, destinado à concessão de financiamento a estudantes de cursos superiores não gratuitos e com avaliação positiva nos processos conduzidos pelo Ministério, de acordo com regulamentação própria. (Redação dada pela Lei $n^{\circ} 13.530$, de 2017). (BRASIL, 2017)

Após sua criação o FIES passou por algumas edições no governo Lula e Dilma, com as Leis $n^{\circ} 11.552$, de 2007, que alterou a Lei de 2001 dando condições de financiamento também para alunos de mestrado e doutorado particulares entre outras providências e a Lei $\mathrm{n}^{\circ} 12.202$ de 2010 que facilitou o abatimento de saldo devedor aos profissionais do magistério público e médicos dos programas de saúde da família; utilização de débitos com o INSS como crédito do FIES pelas instituições de ensino.

Uma das mudanças significativas durante o governo Lula em relação aos agentes financiadores do FIES, foi a criação do FNDE, Fundo Nacional do Desenvolvimento da Educação, que passou a ser o agente operador, também tratou da ampliação dos bancos financiadores como Caixa Econômica Federal e Banco do Brasil. Tais medidas estimularam as oportunidades de vagas a base dos financiamentos, o que provocou um aumento em matrículas e instituições de ensino superior privadas em todo país, já em crescimento desde o governo anterior.

Atualmente o FIES teve sua reedição mais recente foi com a medida provisória $\mathrm{n}^{\mathrm{o}} 785$ de 2017 no governo Temer, e foi convertida a Lei $n^{\circ} 13.530$ de 7 de dezembro de 2017, que revoga todas as Leis e Medidas Provisórias anteriores, mas mantém seu caráter incentivador de crédito a instituições privadas ao abrir as oportunidades para agentes operadores de quaisquer instituições financeiras autorizadas pelo Banco Central do Brasil, conforme é citado no parágrafo único da seção II da referida Lei.

"Parágrafo único. Para fins do disposto nesta Lei, consideram-se agentes financeiros operadores as instituições financeiras autorizadas pelo Banco Central do Brasil, que serão selecionadas nos termos do art. 15-K desta Lei.” (BRASIL, 2017).

Além da abertura para mais instituições financeiras privadas na Lei $\mathrm{n}^{\circ} 13.530$ o governo Temer também estabeleceu nova política de cobrança de juros e pagamento de dívidas, buscando estimular o crédito e novas vagas em instituições privadas. Todas essas medidas podem ser analisadas em uma questão de comparativos de vagas, onde instituições públicas apresentam defasagem em tais números em relação a instituições privadas que recebem financiamento do governo. 
Um valor de financiamento maior pelo governo poderia estar sendo investido em cursos e programas de instituições públicas, preocupando-se com o desenvolvimento educacional e intelectual da educação superior no país, no entanto, ao se tratar de investimento do capital privado, como bancos, é possível verificar que o objetivo governamental acaba por fomentar as instituições privadas e o mercado da educação, no qual as políticas são executadas infelizmente com a preocupação somente econômica.

\section{Governo Lula, PROUNI e REUNI}

O governo Lula iniciou-se em 2003 com promessas e perspectivas de mais oportunidades para a educação, em relação à expansão das instituições de ensino superior públicas e maior acesso a população de baixa renda. Dois programas principais foram de estímulo à expansão do ensino superior, o PROUNI, Programa "Universidade para Todos", e posteriormente o REUNI, Programa de Apoio aos Planos de Reestruturação e Expansão das Universidades Públicas. Através destes programas o governo pretendia atender as demandas de vagas e matrículas em Instituições de Ensino Superior, sejam elas públicas ou privadas, no entanto, o que se observou foi uma discrepante diferença no quantitativo oferecido e investido pelo governo em relação ao patrimônio público e o âmbito privado.

\footnotetext{
Ao longo do governo Lula, se por um lado se retomou certo nível de investimento nas universidades federais promovendo a expansão de vagas, a criação de novas instituições e a abertura de novos campi no âmbito do Programa "REUNI", por outro lado deu-se continuidade ao estímulo à iniciativa privada que acelerou o processo de expansão de vagas e de instituições recebendo alento adicional com o Programa "Universidade para todos", o PROUNI, um programa destinado à compra de vagas em instituições superiores privadas, o que veio a calhar diante do problema de vagas ociosas enfrentado por várias dessas instituições. (SAVIANI, 2010, p. 14).
}

De acordo Saviani (2010), apesar do REUNI ter incentivado a necessária expansão das instituições de ensino superior públicas com a criação de novos campi, vagas e reestruturação tanto física como equipamental e de pessoal, devido anos de descaso e sucateamento nos governos anteriores, o governo Lula manteve as políticas de incentivo ao setor privado com o PROUNI, que investia dinheiro público em instituições de ensino superior privadas para ocupar vagas ociosas, e ainda fornecia benefícios fiscais, o que rendeu uma relevante maior quantidade de matrículas nessas instituições em relação às públicas. 
O PROUNI foi lançado em 13 de janeiro de 2005 com a Lei $n^{\circ} 11.096$, e tinha por objetivo conceder bolsas de estudo parciais para estudantes de graduação em instituições de ensino privadas, para "brasileiros não portadores de diploma de curso superior, cuja renda familiar mensal per capita não exceda o valor de até 1 (um) salário-mínimo e 1/2 (meio)" (BRASIL, 2005).

\begin{abstract}
Art. 1o Fica instituído, sob a gestão do Ministério da Educação, o Programa Universidade para Todos - PROUNI, destinado à concessão de bolsas de estudo integrais e bolsas de estudo parciais de $50 \%$ (cinquenta por cento) ou de $25 \%$ (vinte e cinco por cento) para estudantes de cursos de graduação e sequenciais de formação específica, em instituições privadas de ensino superior, com ou sem fins lucrativos (BRASIL, 2005).
\end{abstract}

O governo assim disponibilizou um investimento alto na expansão de matrículas do ensino superior em instituições privadas, pois além do pagamento parcial das mensalidades para os alunos bolsistas, também forneceu condições fiscais em relação a isenção de impostos para as instituições que aderissem ao programa, conforme a Lei $n^{\circ} 11.096 / 2005$ citado no artigo $8^{\circ}$ :

\begin{abstract}
Art. $8^{\circ} \mathrm{A}$ instituição que aderir ao Prouni ficará isenta dos seguintes impostos e contribuições no período de vigência do termo de adesão: (Vide Lei ${ }^{\circ} 11.128$, de 2005) I - Imposto de Renda das Pessoas Jurídicas; II - Contribuição Social sobre o Lucro Líquido, instituída pela Lei $\mathrm{n}^{\circ} 7.689$, de 15 de dezembro de 1988; III Contribuição Social para Financiamento da Seguridade Social, instituída pela Lei Complementar $\mathrm{n}^{\circ} 70$, de 30 de dezembro de 1991; e IV - Contribuição para o Programa de Integração Social, instituída pela Lei Complementar $\mathrm{n}^{\circ} 7$, de 7 de setembro de 1970 (BRASIL, 2005).
\end{abstract}

Além de benefícios fiscais, o PROUNI também dava prioridade no FIES para as instituições parceiras em relação ao recebimento de recursos do financiamento, essas medidas provocaram um crescimento nunca antes visto em matrículas de ensino superior privado, com a criação de novas faculdades e novos cursos, no entanto, em relação aos cursos oferecidos a educação no país ficava refém das orientações do mercado.

Outros problemas se apresentaram durante a aplicação do PROUNI, apesar do seu caráter social oportunizando alunos de baixa renda estudarem em instituições privadas, a preocupação com a permanência desses alunos não o foi prioridade, a falta de recursos para se manterem e demais condições sociais ou educacionais ocasionaram uma taxa de evasão, na qual após o comprometimento financeiro do governo, as instituições acabavam com vagas ociosas, e não havia arrecadamento de imposto. 
A principal crítica dirigida a essa iniciativa governamental é a de que os recursos que deixarão de ser arrecadados com a isenção de impostos poderiam ser aplicados na ampliação da oferta de vagas nas instituições públicas. Portanto, para alguns críticos da proposta, o Estado estaria comprando vagas já existentes e ociosas, e ao mesmo tempo oferecendo um serviço de qualidade duvidosa. (BARROS, 2015, p. 372).

De acordo cita Barros (2015) o PROUNI não atendeu as expectativas da expansão do ensino superior em relação às demandas educacionais, a formação do aluno e ao cunho social, apesar de facilitar matrículas em cursos superiores, as instituições privadas envolvidas por muitas vezes não correspondiam com estrutura e capacitação, e sim somente ao estímulo do retorno financeiro, investimento esse que poderia estar sendo focado em maior importância para as instituições públicas.

O governo Lula buscou atender as demandas de investimento nas instituições de ensino superior públicas através do REUNI, que foi implantado em 2007 pelo Decreto no 6.095 de 24 de abril, após um grupo de trabalho interministerial ter sido instituído para realizar um diagnóstico da educação superior no país e elaborar um plano de ação que contemplasse as IES públicas.

O Reuni, instituído pelo Decreto $n^{\circ} 6.095$, de 24 de abril de 2007, é uma das ações que integram o Plano de Desenvolvimento da Educação (PDE), e tem como objetivo principal a criação de condições para a ampliação do acesso e permanência do estudante na Educação Superior, no nível de graduação, bem como o melhor aproveitamento da estrutura física e dos recursos humanos existentes nas universidades federais. (BARROS, 2015, p. 374)

Conforme a citação de Barros (2015), os objetivos do REUNI além da expansão de vagas nas IES públicas também consistiam em melhorar a estrutura física e humana das instituições, ou seja, valores altos em investimentos para diminuir a evasão dos cursos e expandir a educação superior.

Todas essas iniciativas foram bem recebidas pelas comunidades universitárias em todo país, no entanto, havia um comprometimento de exigências e contrapartidas as quais as instituições deveriam se submeter ao planejamento governamental para que fossem contempladas ao programa.

Art. 4 $\mathrm{O}$ plano de reestruturação da universidade que postule seu ingresso no Programa, respeitados a vocação de cada instituição e o princípio da autonomia universitária, deverá indicar a estratégia e as etapas para a realização dos objetivos referidos no art. 1ํ․ (BRASIL, 2007) 
Segundo o Decreto $n^{\text {o }}$ 6.095/2007, as IES deveriam apresentar um planejamento de cumprimento de metas, matrículas e redução das taxas de evasão em contrapartida dos recursos adquiridos para novos campi e cursos. Esse comprometimento com os planos de governo fez com que muitas universidades dessem prioridade para cursos de cunho tecnológico que atendessem o mercado e a estrutura física investida pudesse ser trabalhada em parcerias com empresas privadas, o que de certo modo, assim como os investimentos do PROUNI, ocasionou uma grande defasagem em cursos na área de humanas e outras demandas que não fossem tão atrativas ao capital da época.

O governo além dos investimentos em IES públicas das capitais com foque no mercado em crescimento buscou também através do REUNI expandir para os interiores dos estados a oferta de ensino superior pública, estimulando as economias locais e aumentando o número de matrículas, o que se tornou bastante relevante para a população de baixa renda e nível intelectual que obteve oportunidades de formação. Apesar dessa expansão ter sido considerada realizada de uma forma não planejada e sem atender as demandas reais educacionais apresentadas em certas regiões, foi com certeza um importante passo para a expansão do ensino superior no país.

Nesse sentido, Programa de Apoio aos Planos de Reestruturação e Expansão das
Universidades Federais (Reuni- 2007) se constituiu como uma política importante,
que tem na expansão do número de vagas das IES federais o seu escopo precípuo.
Desse modo, o programa contribuiu para alavancar o número de matrículas nas IES
federais, quando observado o período entre $2007-2010$ verifca-se um aumento
percentual no número de matrículas entorno de $46 \%$. Todavia, esse crescimento não
é acompanhado de proporcional investimento na contratação de professores e
técnicos-administrativos, agravando, entre outros problemas, a precarização do
trabalho. Na prática, para a adesão das IES ao Reuni faz-se necessário a
apresentação de um plano comprometido com as metas do programa, enquanto os
repasse de verbas para sua implementação fica condicionado à capacidade financeira
do MEC (MORAES, 2015, p. 25).

Diante do exposto pelo autor, o REUNI tem em sua proposta a oportunidade de contornar muitos dos problemas da educação superior pública no Brasil, com investimento, interiorização, mas devido problemas ainda de ordem de execução e planejamento o mesmo ainda sofre com a não concretização dos seus reais objetivos na expansão das IES e transformação da educação no país. Somente quando houver reais interesses em um plano de governo que trabalhe em longo prazo para modificar paradigmas infelizes da educação e não tratá-la como objeto de mercado ou peça eleitoreira, a população do país poderá usufruir de uma educação de qualidade, sem políticas de troca e sim como ferramenta de desenvolvimento humano de uma nação. 


\section{A Educação à Distância}

Em se tratando de expansão da educação superior no país durante o governo Lula é necessário falar sobre a educação à distância e como seu estímulo em instituições privadas, colaboraram com os altos índices de matrículas nesse período, bem como novos cursos. No entanto não foi somente no setor privado que a educação a distância se expandiu nesse período, em 2006 um Decreto presidencial instituiu a UAB, Universidade Aberta do Brasil para trabalhar em parceria com Institutos Federais de Educação na oferta de mais cursos superiores.

Desde 2003, houve enorme crescimento da oferta de cursos a distância, predominantemente no setor privado. No entanto, com a criação da Universidade Aberta do Brasil (UAB), por meio de parceria entre instituições formadoras (IFES, CEFETs e IES Estaduais) e sistemas de ensino estaduais e municipais, vem crescendo a oferta de educação superior pública em diferentes regiões e municípios do país. A UAB foi instituída pelo Decreto $n^{\circ} 5.800$, de 08 de junho de 2006, com o intuito de oferecer cursos para camadas da população que têm difculdades de acesso à formação universitária, através da modalidade da Educação a Distância (EaD). (BRASIL, 2006 apud BARROS, 2015, p. 375).

Barros (2015) cita que além do crescimento nas ofertas de cursos à distância do setor privado e público com as parcerias entre instituições formadoras essa modalidade também oportunizou uma das políticas de governo com o REUNI, que era a interiorização da oferta de cursos superiores, que poderiam ser levados a cidades e regiões mais distantes da capital sem necessariamente a instalação de novos campi, e sim somente polos para manterem esse tipo de formação, o que evitava mais investimentos.

Apesar de ser uma iniciativa inovadora a modalidade EAD contou com diversas dificuldades, pois a expansão ocorrida também se deu de forma não planejada devido a forma de institucionalização da oferta, com pagamentos de profissionais com bolsas financeiras, falta de vínculo e cronogramas em longo prazo, o que dificultou seu acompanhamento pelo governo e pôs em dúvida a qualidade da formação dos cursos oferecidos.

Dois fatores marcaram essas experiências: a tentativa de expandir, com rapidez, o acesso ao ensino e a necessidade de instalação de infraestrutura que suportasse a capilarização de um sistema de EaD no país. No primeiro caso, a expansão foi acompanhada pela crescente falta de qualidade na oferta: quanto mais alunos, menos os sistemas respondiam à formação mais adensada. Da mesma maneira, a capilarização da infraestrutura em território nacional, bem como os recursos humanos disponíveis não atendiam às demandas pedagógicas dos alunos, redundando em abandono significativo dos cursos (ALONSO, 1996 apud ALONSO, 2010, p. 1333). 
Diante do exposto por Alonso (2010), dois fatores principais marcam as experiências da EAD com alguns obstáculos, uma maior quantidade de alunos procurando esse tipo de formação, devido a questão de tempo e localização geográfica, e em consequência as dificuldades de execução da formação, falta de estrutura e recursos pedagógicos, devido a não atenção e planejamento correto em relação à expansão dessa modalidade.

Apesar de a EAD ter elevado os índices de matrículas e cursos superiores no governo Lula, grande porcentagem desses cursos era da área de humanas e formação de professores, como licenciaturas, cursos de pedagogia, serviço social e administração, por serem cursos baratos em sua oferta no sentido estrutural, e para atender demandas do mercado, o que limitava o crescimento da educação superior no sentido de desenvolvimento científico e intelectual, em relação a ciências, engenharias e outras áreas de estudo.

\section{A Educação Profissional}

Ao se tratar da expansão de instituições de ensino superior no governo Lula, uma das modalidades que teve um crescimento significativo no seu número de campi instalados foi à educação profissional, na qual se enquadra o ensino técnico e tecnológico, foram criados e reestruturados muitos Institutos Federais que oferecem cursos de licenciatura e tecnologias, atribuindo muitas matrículas e atingindo cidades e regiões menos favorecidas de cursos superiores.

Uma das primeiras medidas para garantir uma maior oferta de cursos superiores dentro da educação profissional foi a emissão do Decreto n $n^{0} 6.095$ de 24 Abril 2007 que "estabelecia as diretrizes para o processo de integração de todas as instituições federais de educação tecnológica para fins de constituição dos Institutos Federais de Educação, Ciência e Tecnologia - IFET, no âmbito da Rede Federal de Educação Tecnológica.”

Com esse Decreto o governo iniciou o processo de reestruturação da rede de educação tecnológica, investindo em mais campi, estrutura física, pessoal e novos cursos, que atendessem as demandas do mercado e dos planos econômicos do governo como o PAC (Programa de Aceleração do Crescimento). 
Otranto (2010), afirma que a nova institucionalidade trazida pelos IFs consiste em um modelo alternativo à universidade de pesquisa que vem sendo implementado na América Latina, nos últimos anos, a partir dos incentivos explícitos do Banco Mundial. A autora comenta que a Lei $\mathrm{n}^{\mathbf{0}} 11.892 / 08$, que cria os IFs, integra um conjunto de medidas normativas que visa concretizar o Plano de Desenvolvimento da Educação (PDE) que o tem como um dos mais importantes componentes educacionais o Plano de Aceleração do Crescimento (PAC). Para essa pesquisadora, os IFs evidenciam mais que um novo modelo institucional. É a expressão maior da atual política pública de EP brasileira, produzindo mudanças altamente significativas na vida e na história das instituições que optaram por aderir à proposta governamental. Ademais, essas mudanças precisam ser acompanhadas mais de perto pela comunidade interna. (SOUZA e SILVA, 2016, p. 21).

Para os autores Souza e Silva (2016), ao se tratar de uma pesquisa sobre as perspectivas dos novos paradigmas trazidos pelos Institutos Federais, eles observam que os incentivos do governo para esse tipo de modalidade tiveram objetivos econômicos em relação a formação de mão de obra para atender as metas de desenvolvimento do país, seja dentro do Plano de Desenvolvimento da Educação (PDE), ou o PAC. No entanto todas essas mudanças no modo como era o ensino profissional trouxeram novas oportunidades em relação a formação acadêmica e mercado de trabalho, seja na capital ou interior que precisam ter a atenção das comunidades envolvidas em sua atuação, para que realmente signifiquem bem mais para a educação do que um formador de diplomas para o mercado.

A Lei $\mathrm{n}^{\circ} 11.892$, de 29 de Dezembro de 2008 foi elaborada com o objetivo de consolidar a educação profissional, pois seu objetivo era "Instituir a Rede Federal de Educação Profissional, Científica e Tecnológica, criar os Institutos Federais de Educação, Ciência e Tecnologia e outras providências". Dentre seus artigos agrega as instituições de ensino profissionais existentes como escolas técnicas, centros federais de educação, entre outras das mesmas modalidades, a incorporarem a rede federal e se estabelecer como Instituto Federal.

A educação profissional e sua expansão de vagas e campi tiveram também certos entraves em seu desenvolvimento, e infelizmente muitos dos entraves foram provocados pelo próprio governo. Uma das ações foi procurar atender as instituições privadas que ficaram de fora desses investimentos, por motivos estruturais, pois para cursos profissionais e tecnológicos, é necessário investimento em laboratórios, equipamentos caros e docentes especializados, as medidas governamentais nesse sentido foram de instituir programas de bolsas, como PRONATEC e cursos extras, em serviços como Sistema $\mathrm{S}$.

De acordo a Lei $n^{\circ} 12.513$ de 26 de outubro de 2011, ela cita no seu artigo $1^{\text {a }}$ que: 
Art. $1^{\circ}$ É instituído o Programa Nacional de Acesso ao Ensino Técnico e Emprego (Pronatec), a ser executado pela União, com a finalidade de ampliar a oferta de educação profissional e tecnológica, por meio de programas, projetos e ações de assistência técnica e financeira.

O PRONATEC tinha por objetivo expandir a oferta de cursos que a própria Rede Federal já ofertava, no entanto eram pagas bolsas, ou seja, auxílios financeiros para alunos e professores que muitas vezes não eram da Rede, o que provocou diversas contestações no meio da educação profissional em relação a qualidade dos cursos oferecidos por esse programa, bem como o comprometimento dos alunos, que recebiam um valor para não desistirem dos cursos.

A grande fatia dos recursos financeiros do PRONATEC era destinada ao Sistema S, um sistema de instituições ligadas à iniciativa privada, indústria, serviços, empresas, agronegócio, cooperativas entre outras, que recebiam os valores para ministrarem cursos, muitas vezes de curta duração e sem avaliação do Ministério da Educação, cursos esses que os próprios Institutos Federais ofertavam gratuitamente com aval do MEC. Essas medidas do governo visavam claramente agradar os empresários, e desagradavam os Institutos que em muitas vezes perdiam recursos, investimentos e parcerias por haver uma concorrência na oferta da formação.

No entanto, apesar de muitas das ações da Rede Federal de Educação Tecnológica serem alvo de diversas auditorias e análises em relação a sua atuação, quantidade de matrículas, alunos formados e sua expansão, os Institutos em sua grande parte continuam a cumprir seu papel na interiorização do ensino, mesmo não ocorrendo de uma forma tão planejada intelectualmente, essas instituições agregam uma formação positiva e mudanças de paradigmas sociais onde conseguem alcançar.

\section{Considerações Finais}

É possível observar através dessa análise entre o intervalo de tempo das implantações de tantos programas que visavam expandir o ensino superior, desde a criação do FIES no governo FHC e os programas dos governos Lula que tiverem continuidade no governo Dilma, que houve uma significativa mudança em relação a quantitativos de instituições e matrículas do ensino superior, em destaque as instituições privadas. 
A quantidade de IES cresceu exponencialmente no setor privado e praticamente dobrou no setor público, isso tudo durante o período entre os anos 2000 e 2013, o qual foi destacado nesse artigo pelos governos os quais passaram, dando enfoque a ações que estimularam o capital e o movimento da economia apesar de iniciativas motivadoras na rede pública educacional. Através de dados dos INEP, a conclusão dessas políticas se mostra graficamente aqui em forma de números.

Figura 1 - Gráfico do crescimento da Quantidade de IES no Brasil

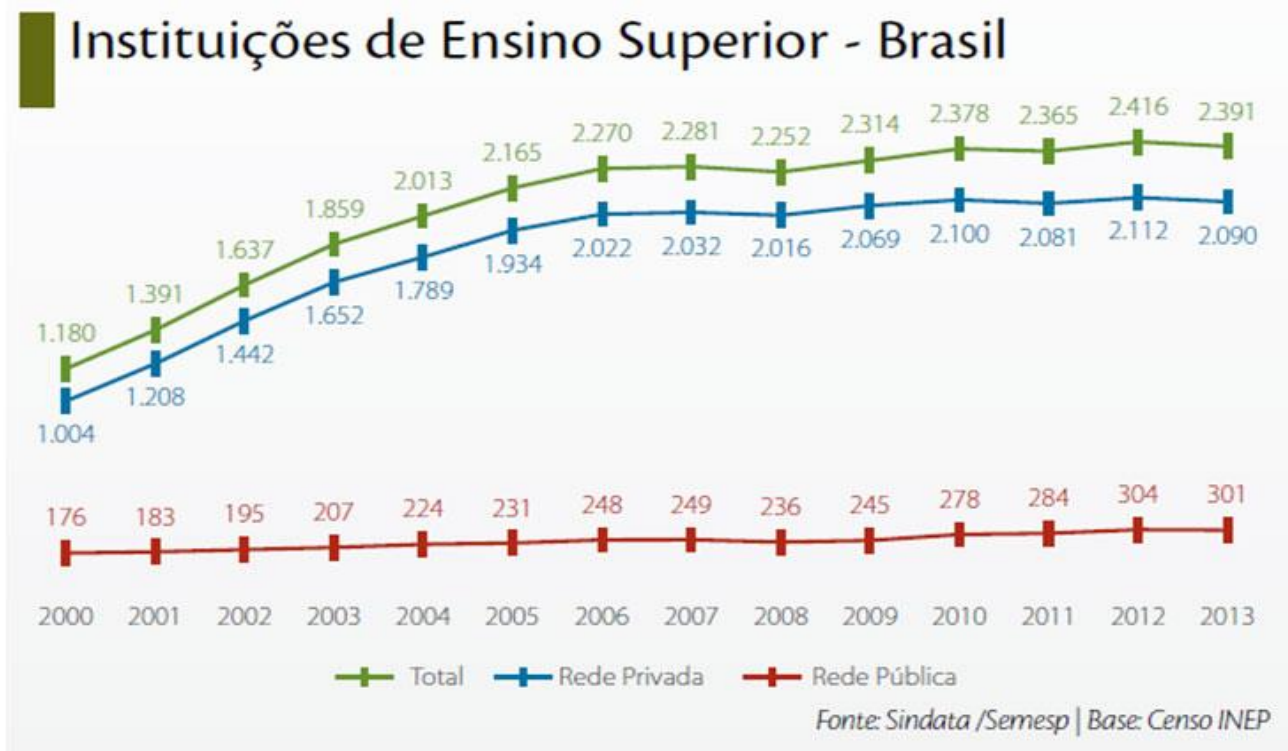

Fonte: Sindata/Semesp, 2016.

A conclusão dessas medidas é que infelizmente ainda não foi aplicado no país um projeto de educação, com uma política de estado e não de governos que se aplique a uma radical mudança na educação, onde haja mais investimento público na educação gratuita e de qualidade que promova desenvolvimento social e não só lucro para empresas privadas onde a educação é tratada como produto. Mesmo diante do considerável crescimento das instituições públicas, também dando abertura aos institutos de educação profissional, as instituições privadas cresceram em números e matrículas utilizando-se de verbas federais que poderiam estar sendo aplicadas para as populações de baixa renda, na formação e mudança de paradigmas em regiões até mais afastadas da capital, formando uma nova geração intelectualmente oportunizada no ensino superior. 
Em muitas cidades sim, essa expansão tão almejada pode ter chegado, no entanto ainda enfrenta barreiras de consolidação diante de programas do próprio governo que estimulam outras instituições, modelos e tipos de cursos mais indicados no mercado, assim como modalidades em educação a distância e cursos sem o devido planejamento e avaliação, como os do PRONATEC, com o advento de bolsas, que embora necessárias em muitos casos acabem por desviar o público do real motivo da formação oferecida, que é capacitação de qualidade.

Todas essas ações e suas consequências dentro do cenário educacional do ensino superior são de extrema importância para o auxílio de projetos de pesquisa que visem trabalhar dentro dessa modalidade, pois para analisar propostas e estudos que visem intervir com essa realidade, o docente, ou pesquisador da educação precisa estar a par de um histórico da educação brasileira e tudo que contribuiu e influenciou a formação nesse período, sejam cursos, vagas, matrículas, financiamentos, incentivos fiscais e instituições. A partir de uma análise política e documental é que o futuro da educação pode ser pesquisado e trabalhado em um sentido mais amplo, intelectual e democrático.

\section{Referências}

ALONSO, K. M. A expansão do ensino superior no Brasil e a EaD: Dinâmicas e lugares. Revista Educação \& Sociedade.V. 31, n. 113, p. 1319-1335, out/dez. 2010. Disponível: http://www.scielo.br/pdf/es/v31n113/14.pdf. Acesso em: 10/11/2017

BARROS, A. S. X. Expansão da Educação Superior no Brasil: Limites e Possibilidades. Revista Educação \& Sociedade. V. 36, n. 131, p. 361-390, abr/jun. 2015. Disponível:http://www.scielo.br/pdf/es/v36n131/1678-4626-es-36-131-00361.pdf. Acesso em: $10 / 11 / 2017$

BRASIL. Casa Civil. Lei n $^{\circ}$ 10.260, de 12 de julho de 2001. . Casa Civil. Lei no 13.530, de 7 de dezembro de 2017. Casa Civil. Lei $n^{\circ}$ 11.096, 13 de janeiro de 2005. Casa Civil. Decreto no 6.095, de 24 Abril de 2007. . Casa Civil. Lei $n^{\circ}$ 11.892, de 29 de Dezembro de 2008. . Casa Civil. Lei $n^{\circ} 12.513$ de 26 de outubro de 2011. 
MORAES, G. C. Mercantilização das Instituições de Ensino Superior Públicas e Privadas no Brasil. Revista três pontos. V.12, n.2, p. 18-31, ago/dez.2015. Disponível em: https://seer.ufmg.br/index.php/revistatrespontos/article/view/3559. Acesso em: 12/11/2017.

SAVIANI, D. A expansão do ensino superior no Brasil: Mudanças e Continuidades. Poíesis Pedagógica, V.8, n.2, p.4-17, ago/dez.2010. Disponível em: https://www.revistas.ufg.br/poiesis/article/view/14035. Acesso em: 14/11/2017.

SOUZA, F. C. S. SILVA, S. H. S. C. INSTITUTOS FEDERAIS: expansão, perspectivas e desafios. Revista Ensino Interdisciplina. V. 2, n. 05, p. 17-26, jul. 2016. Disponível em: http://dx.doi.org/10.21920/recei72016251726. Acesso em: 12/11/2017.

\section{Como citar este artigo (Formato ABNT):}

MARQUES, Maria Alice de Freitas. Políticas Educacionais Nos Governos Lula e Dilma: Impactos Na Expansão Do Ensino Superior E Profissional. Id on Line Rev.Mult. Psic., 2018, vol.12, n.41, p.661676. ISSN: 1981-1179.

Recebido: 10/07/2018

Aceito 11/07/2018 